This item was submitted to Loughborough's Research Repository by the author.

Items in Figshare are protected by copyright, with all rights reserved, unless otherwise indicated.

\title{
Modelling infrared radiation from the combustion products in a spark ignition engine
}

PLEASE CITE THE PUBLISHED VERSION

PUBLISHER

(C) Society of Automotive Engineers

VERSION

NA (Not Applicable or Unknown)

LICENCE

CC BY-NC-ND 4.0

\section{REPOSITORY RECORD}

Blunsdon, C.A., John C. Dent, and W. Malalasekera. 2019. "Modelling Infrared Radiation from the Combustion Products in a Spark Ignition Engine". figshare. https://hdl.handle.net/2134/5749. 
This item was submitted to Loughborough's Institutional Repository (https://dspace.lboro.ac.uk/) by the author and is made available under the following Creative Commons Licence conditions.

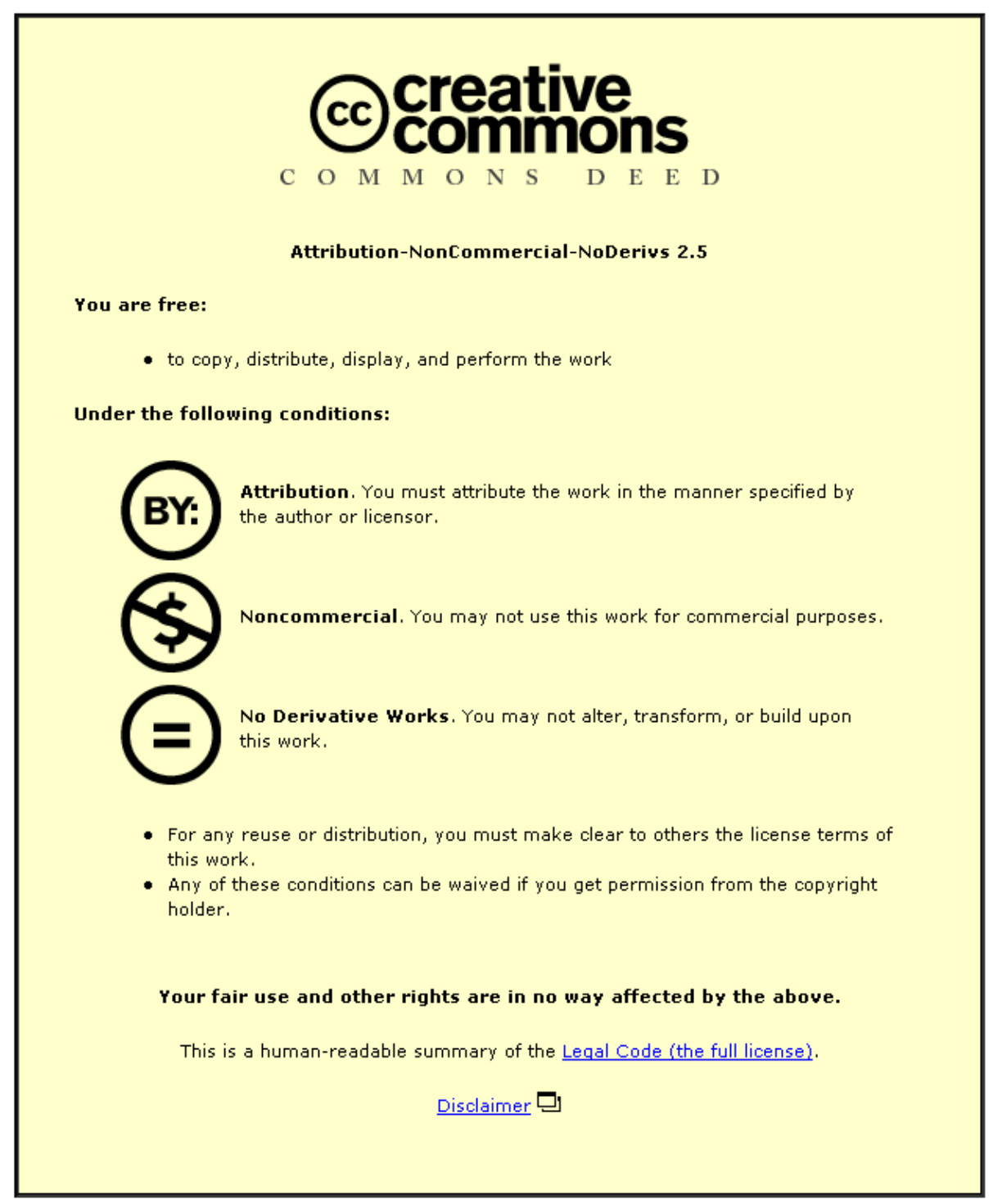

For the full text of this licence, please go to: http://creativecommons.org/licenses/by-nc-nd/2.5/ 


\section{Modelling Infrared Radiation from the Combustion Products in a Spark Ignition Engine}

Authors

1. C. A. Blunsdon

2. J.C. Dent

3. W.M.G. Malalasekera
Address

Department of Mechanical Engineering Loughborough University of Technology Loughborough, Leicestershire LE11 3TU United Kingdom

Department of Mechanical Engineering Loughborough University of Technology Loughborough, Leicestershire LE11 3TU United Kingdom

Department of Mechanical Engineering Loughborough University of Technology Loughborough, Leicestershire LE11 3TU United Kingdom 


\begin{abstract}
Application of the engine CFD code KIVA II with the inclusion of the SHELL model for autoignition chemistry, and the discrete transfer radiation heat transfer model, has enabled the technically important problem of non luminous radiation from the major emitting species $\mathrm{CO}_{2}$ and $\mathrm{H}_{2} \mathrm{O}$ in the combustion products within the cylinder of a spark ignition engine to be considered as a combustion diagnostic aid, and also as a method of controlling individual cylinder Air/Fuel ratio.

Results from a parametric study using CFD have been found to corroborate the experimental findings of other workers over a range of operating conditions including knock.
\end{abstract}

\section{INTRODUCTION}

In order to meet strict legislation in regard to automotive exhaust pollutant emissions, current spark ignition engines are fitted with a 'three way' catalyst which requires the engine to operate in a narrow band of air/fuel ratio around stoichiometric. Control of the air/fuel ratio is through a feedback sensor detecting the oxygen concentration in the exhaust pipe, so that tight control on individual cylinder air/fuel ratio is not achieved.

To obtain closer control of individual cylinder air/fuel ratio and combustion the application of a number of diagnostic methods have been attempted, including the use of light emission in the visible part of the electromagnetic spectrum. This is attractive in that modern optical fibre and detector components are cheap, hence detector electronics can be quite remote from the hostile and electrically noisy environment of the engine compartment $[1,2]$.

Increasingly, environmental concerns in regard to global warming have resulted in renewed interest in lean mixture operation as a means of reducing carbon dioxide emissions from engines. In the spark ignition engine, light emission from the combustion products fall off dramatically with mixture leanness [3], and the burned gas zone is fragmented.
Furthermore it is necessary for the engine to operate over a range of air/fuel ratios during transient operation, when the vehicle is undergoing acceleration/deceleration processes, hence a significant loss of signal sensitivity in a control context is unacceptable. An alternative diagnostic that can be exploited for air/fuel ratio and combustion control is the non-luminous infra-red emission of carbon dioxide $\left(\mathrm{CO}_{2}\right)$ and water vapour $\left(\mathrm{H}_{2} \mathrm{O}\right)$ in the high temperature combustion products in the cylinders of an engine. The detected radiation intensity at the cylinder surface is the integrated effect of emission from that portion of the burned volume actually viewed by the detector, therefore fragmentation of the enflamed volume presents less of a problem for infrared detection than for the detection of visible light. The concentration of $\mathrm{CO}_{2}$ and $\mathrm{H}_{2} \mathrm{O}$ in the combustion products vary in a known manner with air/fuel ratio relative to stoichiometric mixture strength [4], irrespective of engine type [5] (spark ignition or Diesel). The advantages of fibre communication and inexpensive signal detection will still apply.

This paper uses Computational Fluid Dynamics (CFD) to explore the suitability of infrared emission as a combustion diagnostic, and for use as a parameter for control of individual cylinder airffuel ratio.

\section{BACKGROUND}

Infra-red emission from gases is electromagnetic radiation in the wavelength range 0.7 to $100 \mu \mathrm{m}$, and is dependent on the molecular structure of the gas and the energy state of its molecules (vibration, rotation, electronic). The intensity of radiation from a particular gas is not continuous with wavelength for a given temperature as in the case of a Black Body emitter, but banded over certain wavelength ranges. The products of hydrocarbon fuels burning with air, produce strong non-luminous radiation principally from carbon dioxide and water vapour, which is dependent on the 


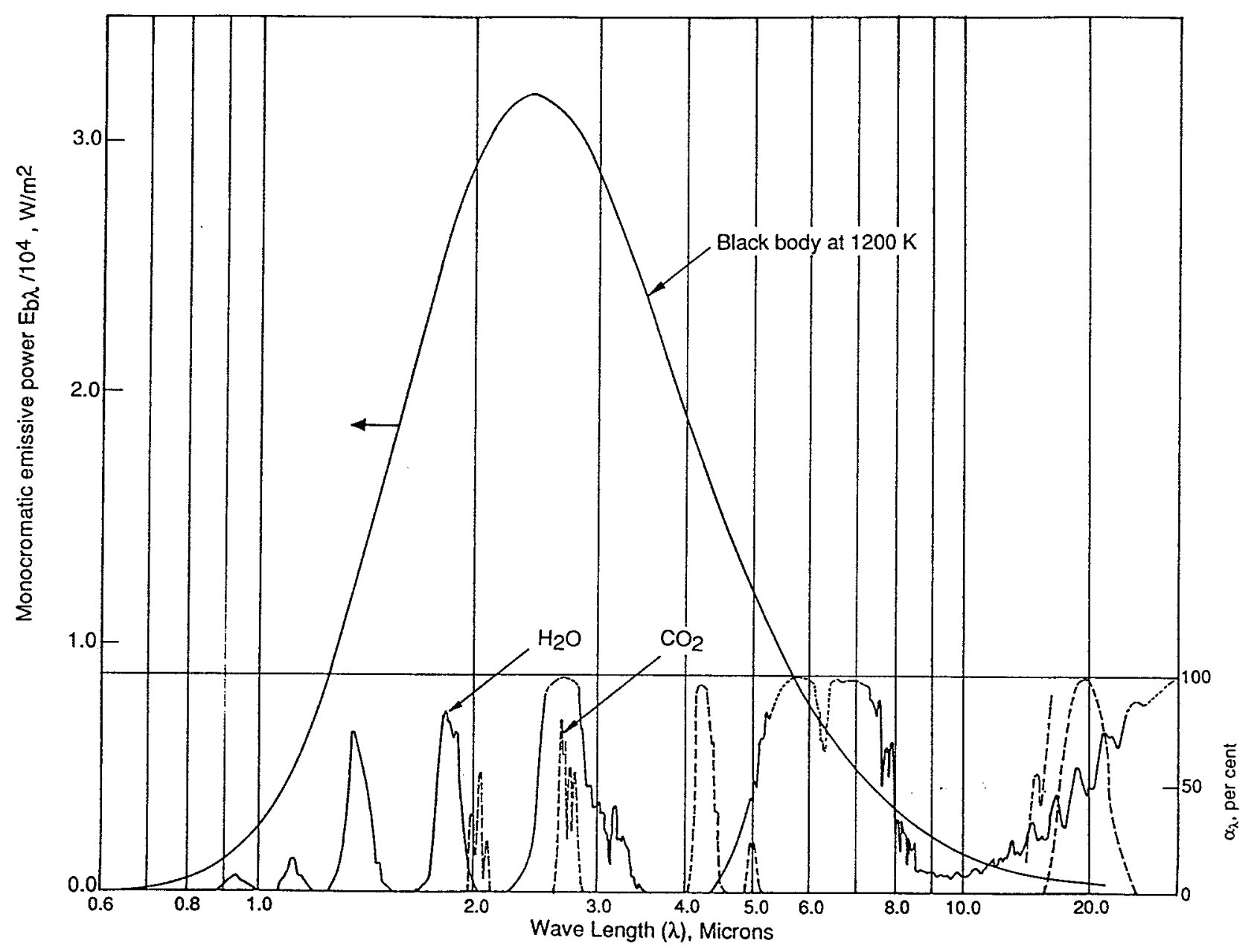

Figure 1 Distribution of Radiative Heat Flux for a Black Body Source and Emission Bands for $\mathrm{CO}_{2}$ and $\mathrm{H}_{2} \mathrm{O}$

concentration of each of these constituents, and the combustion system pressure and temperature. These ideas are summarised in Figure 1.

Early systematic experimental studies by Marvin et al [6] and Baker and Laserson [7] showed conclusively that in the spark ignition engine the primary source of non-luminous radiation arose from $\mathrm{CO}_{2}$ and $\mathrm{H}_{2} \mathrm{O}$ in the combustion products, under normal and 'knocking' combustion. Radiation from incandescent soot was negligible in normal combustion, but is significant during 'knock' due to rapid pyrolysis.

More recently Remboski et al [2] using a spark ignition engine with a fibre optic connection between the cylinder head and a remote inexpensive photodetector, investigated the variation of optical intensity with change in engine operating variables, as a combustion analysis and control tool. The authors noted that the $0.9-1 \mu \mathrm{m}$ sensitivity band of the optical detector also fell within the weak infra-red band for $\mathrm{H}_{2} \mathrm{O}$ (Figure 1). Typical data obtained by these authors is shown in Figure 2 for the conditions given in Table 1. The relative phasing of the luminosity output with cylinder pressure and heat release during the combustion and expansion phases of the engine cycle are of interest, and corroborate the earlier findings of Marvin et al [6]. The lag in the luminosity signal being attributed to the non-luminous emission from $\mathrm{H}_{2} \mathrm{O}$ (and $\mathrm{CO}_{2}$ ), which are related to cylinder pressure and combustion temperature.

Table 1 Engine test conditions of Remboski el al [2]

\begin{tabular}{|l|l|}
\hline Engine Speed RPM & $750,1500,2400^{*}$ \\
\hline Intake manifold & 70,85 WOT* $^{*}$ \\
Pressure (kPa) & \\
\hline Air Fuel ratio & 13.0, \\
& $14.6^{*}$ (stoichiometric), \\
& $16.5,18.0$ \\
\hline Spark Timing & $\mathrm{MBT}-10^{\circ}, \mathrm{MBT}^{*}$, \\
& $\mathrm{MBT}+10^{\circ}$ \\
\hline EGR (percent) & $0^{\star}, 5,10,15$ \\
\hline * Denote baseline operating condition \\
WOT (wide open throttle) \\
MBT (minimum spark advance for best torque) \\
\hline
\end{tabular}




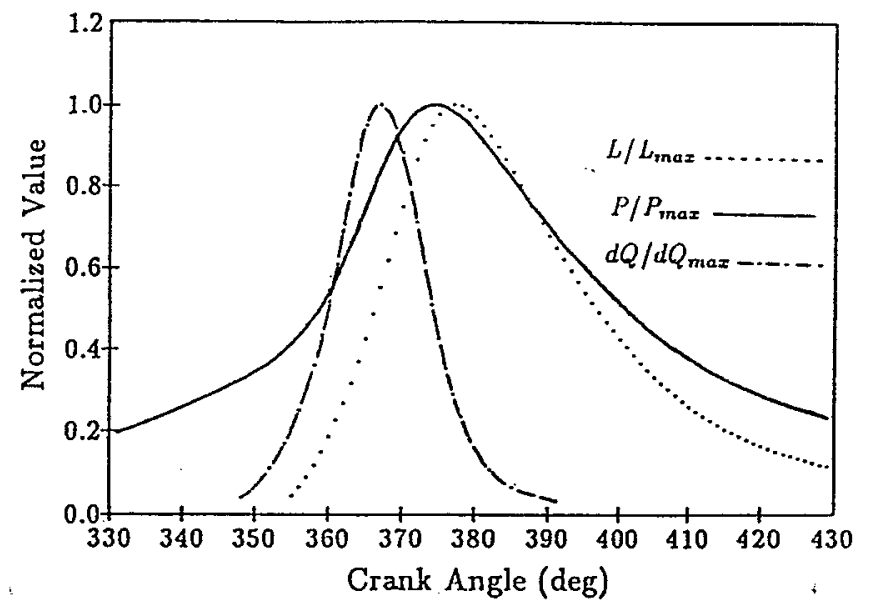

(a) Comparison of Pressure (P), Rate of Heat Release (Q) and Luminosity (L) for the Baseline Operating Condition.

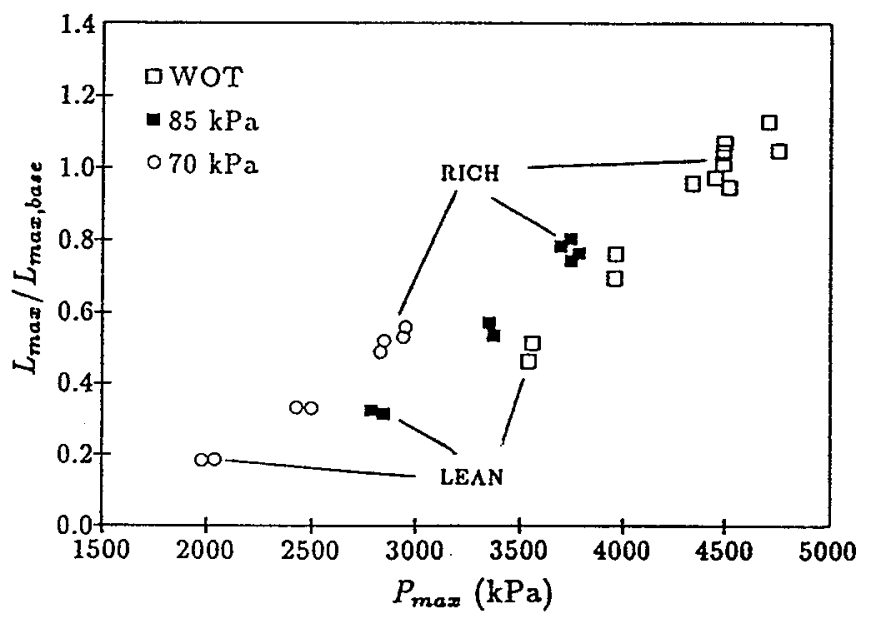

(b) Correlation of $L_{\max } \cdot L_{\max }$,base and $P_{\max }$ with $P_{\text {int }}$ and Air/Fuel ratio Variations at 2400 RPM

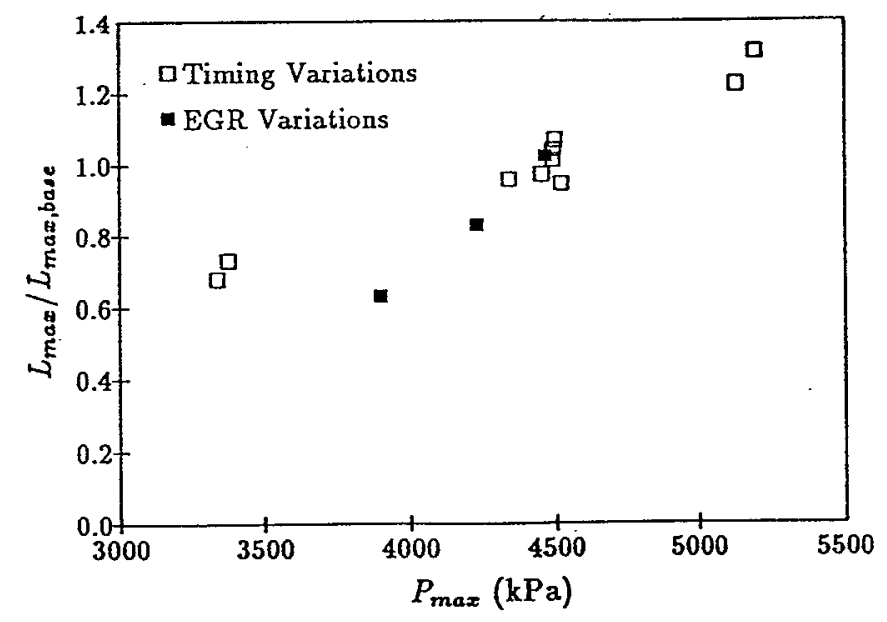

(c) Correlation of $L_{\max } / L_{\max }$,base and $P_{\max }$ with EGR and Spark Timing Variations at 2400 RPM, WOT

Figure 2 Data of Remboski et al [2]
At constant engine speed the variation of nondimensional luminosity (normalised with the value at the baseline operating condition, see Table 1) with maximum cylinder pressure $P_{\max }$, for variation of:

- Air/fuel ratio (at MBT timing) and throttle setting (load)

- Exhaust gas recirculation

- Ignition timing

All produce results which show expected trends, with normalised luminosity increasing linearly with $P_{\max }$ in all cases, showing the strong effect of combustion pressure and temperature on the detected signal level.

Nutton and Pinnock [1] using a semiconductor colour sensor with two stacked photo diodes having spectral responsivities at $0.6 \mu \mathrm{m}$ (visible red end of the spectrum) and at $0.9 \mu \mathrm{m}$ (infrared weak $\mathrm{H}_{2} \mathrm{O}$ band) undertook an extensive study relating optical intensity, cylinder pressure and mass fraction burned as a function of crank angle as part of a wider investigation of engine control strategy. Their observations support the findings discussed above, that peak luminosity lags peak cylinder pressure.

\section{CFD MODELLING}

This was undertaken using the Los Alamos KIVA Code [8] into which was incorporated the Shell Autoignition sub-model [9] with the CFD implementation of Schapertons and Lee [10]. A discrete transfer radiation model [11] was incorporated into KIVA, using a mixed grey gas description [12] for the radiative absorption/emission of $\mathrm{CO}_{2}$ and $\mathrm{H}_{2} \mathrm{O}$. While the grey gas approximation has the disadvantage that the banded contributions of radiation from $\mathrm{CO}_{2}$ and $\mathrm{H}_{2} \mathrm{O}$ cannot be separated, i.e. the simulation of radiation detected behind a narrow band filter centred on a wavelength of interest in the banded spectra of $\mathrm{H}_{2} \mathrm{O}$ and $\mathrm{CO}_{2}$ cannot be achieved. Nevertheless, the grey gas description is computationally economic and adequate for the initial study presented here. A banded description of radiation [13] can be considered in the future if required.

The implementation of the Shell scheme and the discrete transfer radiation model in KIVA have been discussed in some detail by the present authors [14] and will for brevity not be repeated here apart from two points:

1. The main combustion model adopted by the Loughborough group $[15,16]$ differs from that used by Schapertons and Lee [10] therefore, the criteria for inhibiting the knock reactions in the unburned gas zone just ahead of the propagating flame front needed to be readjusted. In this study knock was inhibited if the local unburned gas temperature exceeded $920 \mathrm{~K}(900 \mathrm{~K})$ and the local concentration of the labile intermediate $Q$ in the Shell scheme exceeded $0.04 \mathrm{~mol} / \mathrm{m}^{3} \quad 0.1$ $\mathrm{mol} / \mathrm{m}^{3}$ ) - the bracketed values being the criteria 


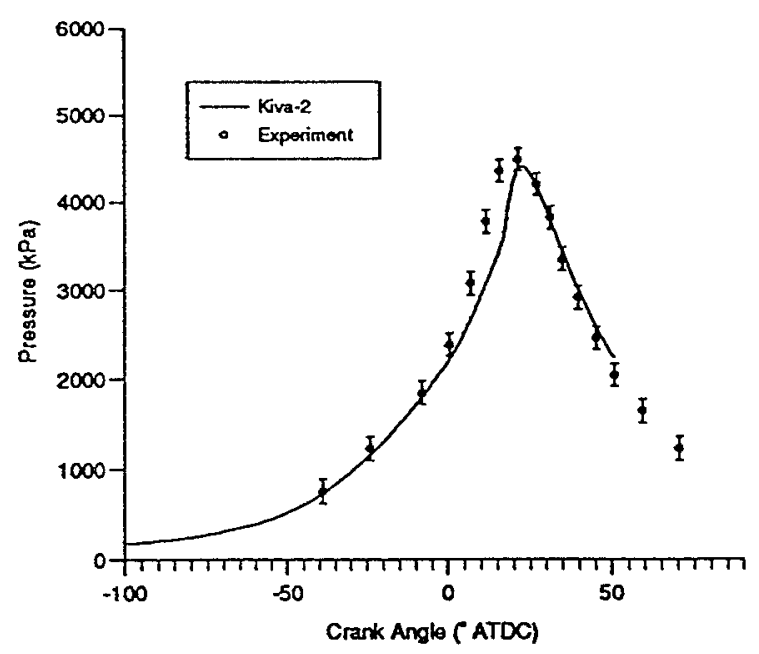

(a) Mean Pressure vs. Crank Angle Spark timing $20^{\circ}$ BTDC, Air/Fuel ratio $=15.5$ Speed $=1500 \mathrm{rpm}$, Compression ratio $=8.7$

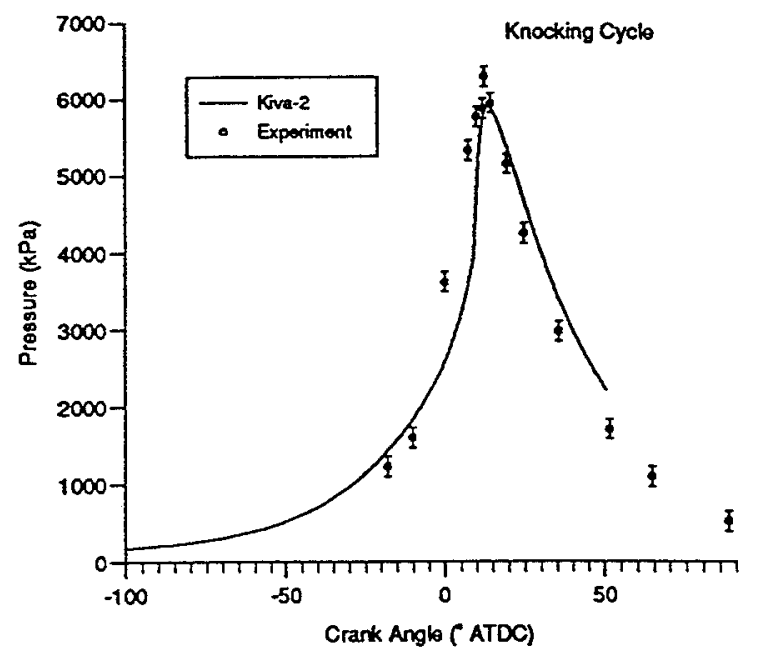

(b) Mean Pressure vs. Crank Angle Spark timing $26^{\circ}$ BTDC, Air/Fuel ratio $=15.5$ Speed $=1500 \mathrm{rpm}$, Compression ratio $=8.7$

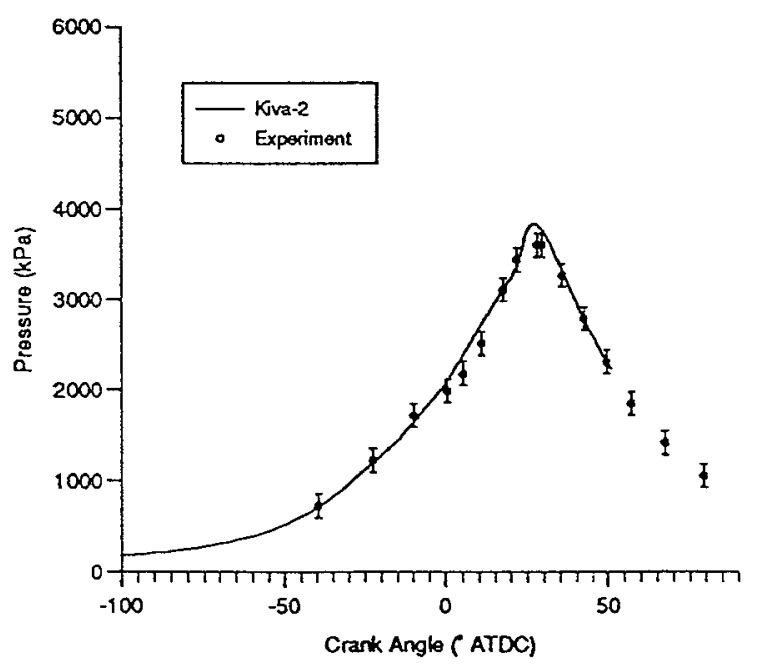

(c) Mean Pressure vs. Crank Angle Spark timing $14^{\circ}$ BTDC, Air/Fuel ratio $=15.5$ Speed $=1500 \mathrm{rpm}$, Compression ratio $=8.7$

Figure 3 Recardo E6 Engine. Mean Pressure against crank angle at three spark timings. adopted by Schapertons and Lee. The implementation of the knock scheme was validated with experiments on a Ricardo E6 engine, and typical results are shown in Figure 3 of computed and experimental cylinder pressures for variation of ignition timing. The computational mesh used for the knock study is shown in Figure 4.

2. In the implementation of the discrete transfer radiation model in reference [14], allowance was

\section{Engine Parameters}

- Compression ratio 8.7

- Stroke $11.11 \mathrm{~mm}$, bore $76.2 \mathrm{~mm}$

- Disc chamber, spark $28 \mathrm{~mm}$ off-centre

- Fuel 98 RON

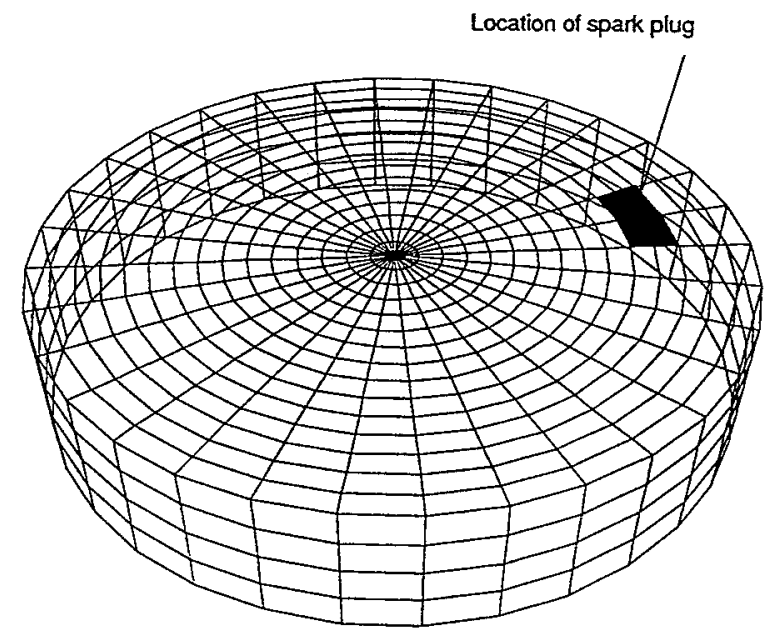

Figure 4(a) Ricardo E6 engine: Computational Mesh at TDC. At the start of the computation there are 11040 cells.

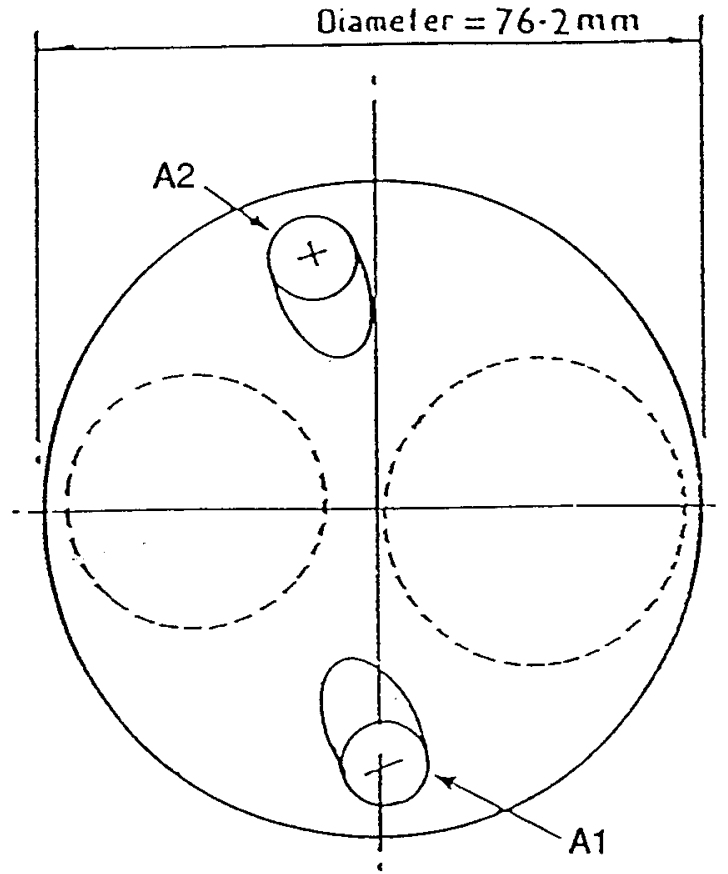

Figure 4(b) Plan of E6 cylinder head A1 $=$ spark plug location $\mathrm{A} 2=$ pressure transducer location 


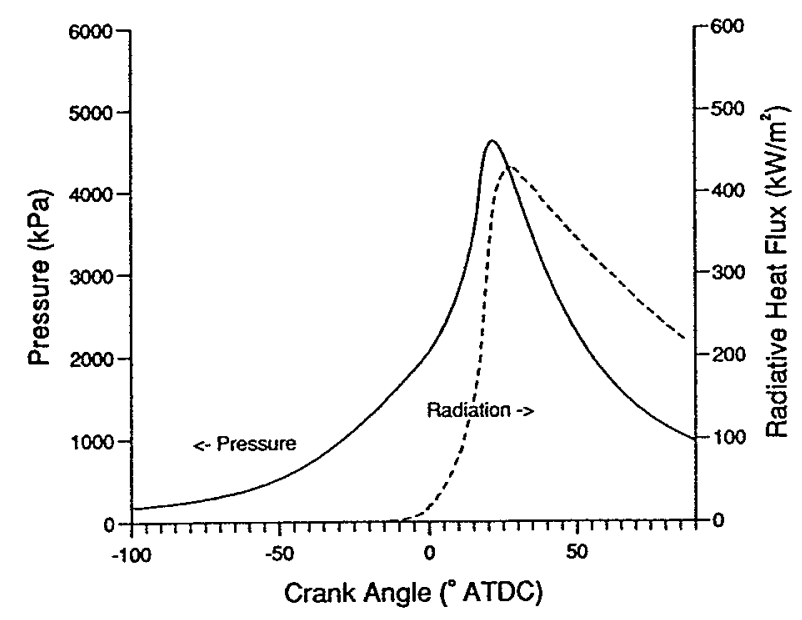

(a) Spark Timing $16^{\circ}$ BTDC

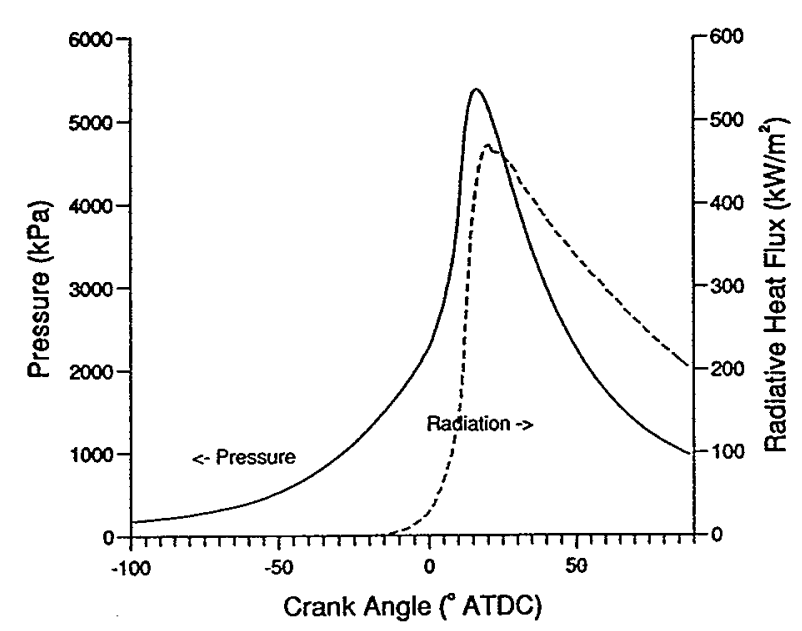

(c) Spark Timing $24^{\circ}$ BTDC

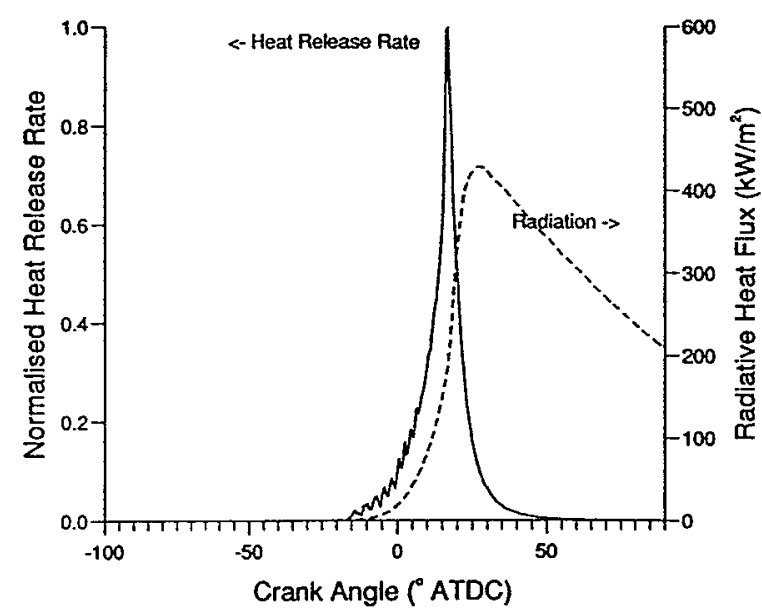

(b) Heat Release Rate and Radiative Heat Flux vs Crank Angle. Spark Timing $16^{\circ}$ BTDC

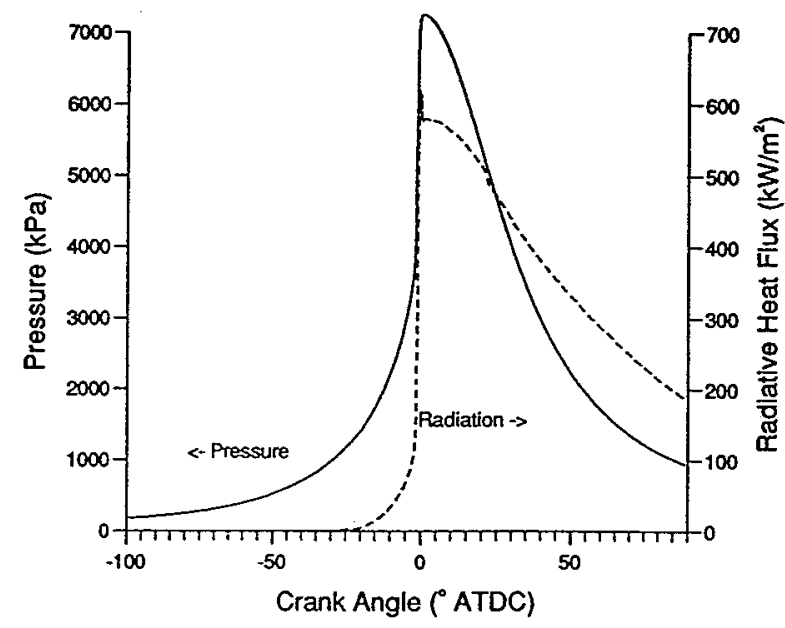

(d) Spark Timing $34^{\circ}$ BTDC Knocking Combustion

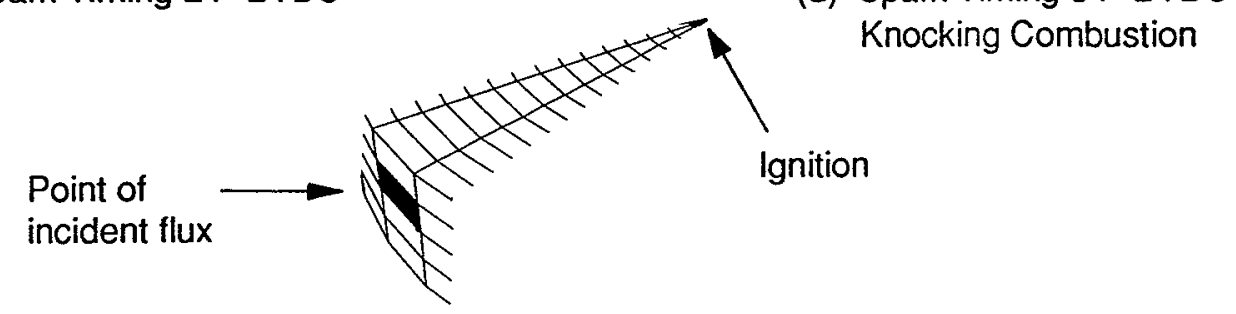

Figure 5 Simulated Pressure and Radiative Haet Flux curves for three spark timings. Central spark plug, air/fuel ratio 15.5, speed $1500 \mathrm{rpm}$, compression ratio $8.7,3 \%$ residuals. Radiation detector on the cylinder wall under the cylinder head.

made for the luminous radiative transfer due to the concentration of soot in the combustion products of the simulated Diesel engine. In the implementation here the assumption is made that soot concentration in the combustion products of a spark ignition engine are negligible, hence the luminous radiative component as dealt with in the emissivity/absorptivity calculation model is not activated.

\section{ENGINE RADIATION MODELLING STUDY}

To conserve computational resources, a disc combustion chamber similar to that of the $E 6$ engine shown in Figure 4 was considered, but with central location of the spark plug enabling symmetry to be exploited in the computation, thus a single sector of the disc chamber computational grid can be used.

Initially the effect of ignition timing on radiation emission was studied at a fixed engine speed of $1500 \mathrm{rpm}$, stoichiometric air/fuel ratio and 3\% 


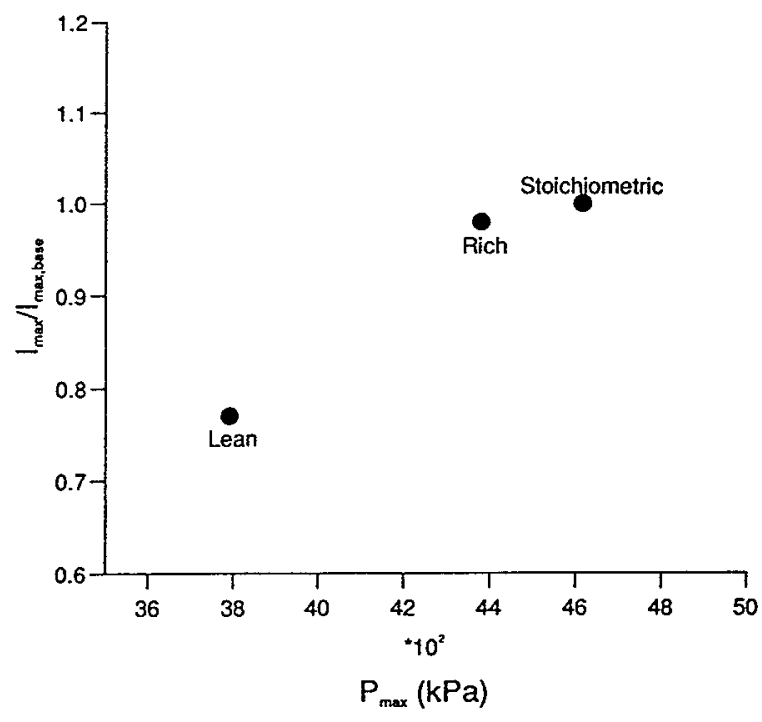

Figure 6(a) Correlation of $I_{\max } / I_{\max }$, base with Air-Fuel Variation, Spark timing $16^{\circ}$ BTDC

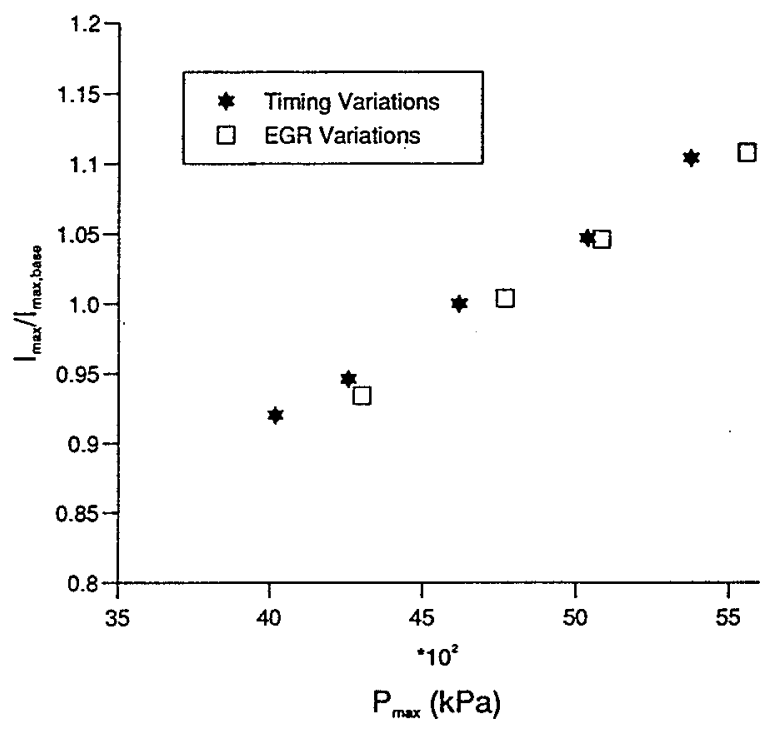

Figure 6(b) Correlation of $I_{\max } / I_{\text {max }}$,base and $P_{\text {max }}$ with EGR and Spark Timing variations

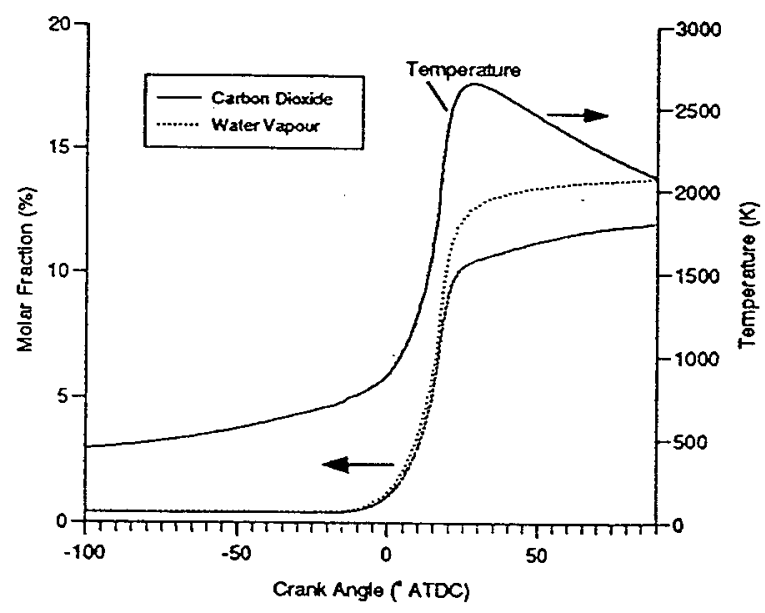

Figure 6(c) Mean Temperature and Combustion Products vs. Crank Angle, Air-Fuel ration $=15.0$ exhaust residuals. Ignition timing was varied between $8^{\circ}$ to $34^{\circ}$ before top dead centre (BTDC). The radiative heat flux was determined over a single cell surface on the cylinder wall, in the clearance space, as shown in Figure 5; also shown in this figure is the variation of radiative heat flux and cylinder pressure with crank angle for the range of spark timings indicated above.

As experimentally observed by Marvin et al [6], Remboski et al [2] and Nutton and Pinnock [1] the radiative heat flux lags cylinder pressure. The rate of change and peak heat flux and its phasing relative to top dead centre (TDC) vary markedly with ignition advance, reflecting similar changes in cylinder pressure with ignition timing that are well known. The occurrence of knock with an ignition timing of $34^{\circ}$ BTDC is clearly seen by the very sharp increase in radiation intensity and its coincidence in phasing with pressure, due to the rapid production of $\mathrm{CO}_{2}$ and $\mathrm{H}_{2} \mathrm{O}$ and temperature rise during autoignition of the end gas. Similar observations were noted in the experiments of Marvin et al [6] and Nutton and Pinnock [1], under knocking conditions.

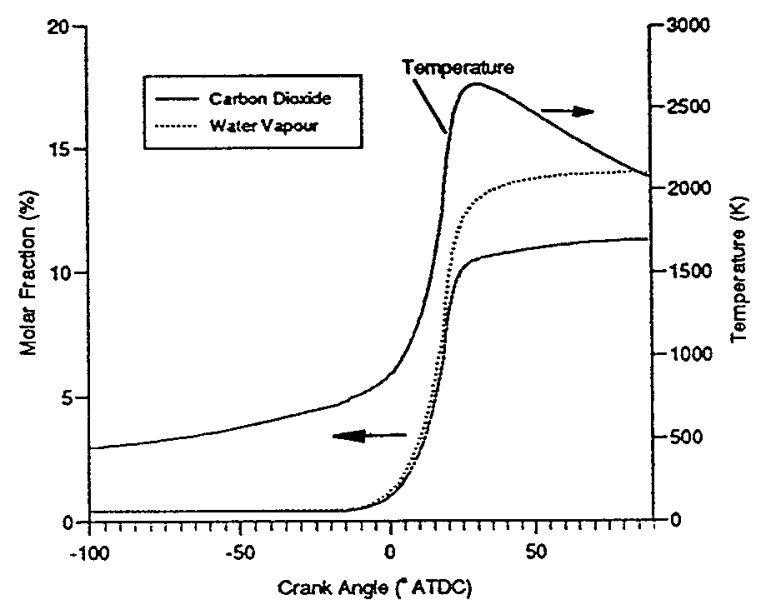

Figure 6(d) Mean Temperature and Combustion Products vs. Crank Angle, Air-Fuel ratio $=14.0$

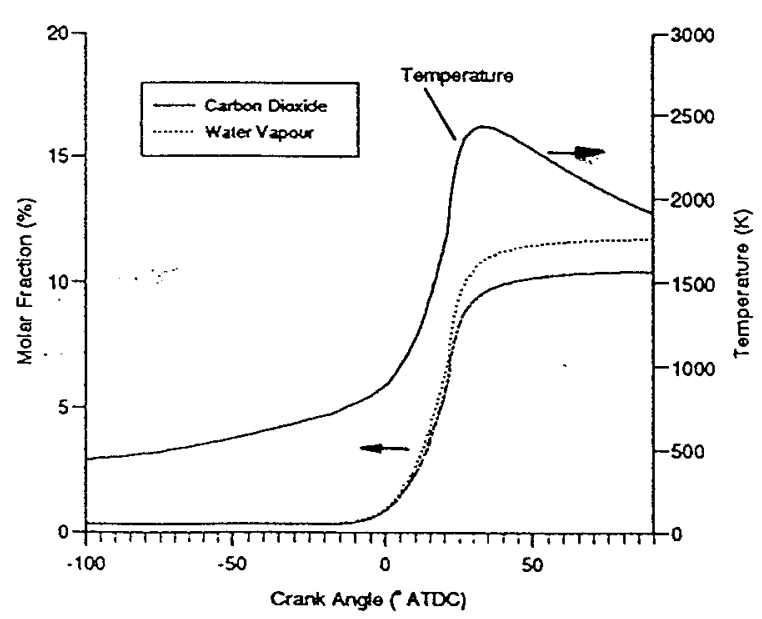

Figure 6(e) Mean Temperature and Combustion Products vs. Crank angle, Air-Fuel ratio $=18.0$. 
A series of simulations were undertaken with parametric variation of stoichiometry $\phi(0.83 \leq \phi \leq$ 1.11), spark timing $\theta_{S}{ }^{\circ}$ BTDC $\left(8^{\circ} \leq \theta_{S} \leq 24^{\circ}\right)$, and exhaust residuals EGR $(0 \leq E G R \leq 10 \%)$ around a baseline condition of $1500 \mathrm{rpm}, \theta_{\mathrm{S}}=16^{\circ} \mathrm{BTDC}$ and $3 \%$ EGR. These results are shown in Figures 6(a) and $6(b)$, where the peak radiative flux $I_{\text {max }}$, is normalised by the peak flux at the baseline condition Imax,base, and plotted against maximum cylinder pressure $\mathrm{P}_{\max }$, for comparison with the results of Remboski et al [2].

The variation in Figure 6(a) is as expected. Combustion temperatures are a maximum at the stoichiometric condition, will be marginally lower for the rich mixture, and much lower than stoichiometric for the lean mixture due to the diluent effect of the excess air. Concentrations of $\mathrm{H}_{2} \mathrm{O}$ and $\mathrm{CO}_{2}$ will be maximum at stoichiometric, marginally different for the rich mixture but significantly lower than stoichiometric for the lean mixture. This is confirmed by the computed results for mean temperature and concentration of $\mathrm{H}_{2} \mathrm{O}$ and $\mathrm{CO}_{2}$ in the cylinder, as a function of crank angle, for the three air/fuel ratios studied. These results are shown in Figures 6(c)-(e). The results in Figure 6(a) do not follow the trend of results given by Remboski et al [2], as the air/fuel ratio study here is conducted at a fixed spark timing. Therefore, cylinder pressures and temperatures will be highest at the stoichiometric condition for which the spark timing would be less retarded than for the rich or lean air/fuel ratios. The diluent effect of mixture weakness also contributes to a reduction in gas temperature.

The trend of radiation flux ratio with $P_{\max }$ for variation in spark timing and EGR, Figure $6(b)$, is similar to that observed experimentally in reference [2], and reflects the relationship between $P_{\max }$ and maximum combustion temperature.

Remboski et al [2] observed that the ratio of $1 / 1 /$ max,base against crank angle lagged the heat release rate (obtained from cylinder pressure analysis) by about $15^{\circ}$ crank angle and attributed this to the delay in the formation of adequate concentrations of $\mathrm{CO}_{2}$ and $\mathrm{H}_{2} \mathrm{O}$, and the increase in combustion temperature. Similar behaviour is observed with the simulation, and confirm the hypothesis concerning increase in concentration of $\mathrm{CO}_{2}$ and $\mathrm{H}_{2} \mathrm{O}$ and temperature level. See Figures $5(\mathrm{~b})$ and $6(\mathrm{c})$.

Of significance as a diagnostic on the progress of combustion is the burned gas volume. As the major concentrations of $\mathrm{CO}_{2}$ and $\mathrm{H}_{2} \mathrm{O}$ will be in this volume, then the radiative flux to a detector from these constituents must be related to the burned gas volume. Defining the burned gas as that region in which temperature is not less than $1100 \mathrm{~K}$, Figure 7 shows the variation of burned gas volume with radiative heat flux for the baseline operating condition. The radiative heat flux increases rapidly with burned gas volume in an approximately linear manner following an initial delay. This occurs because the instantaneous volume of the bumed gas is less than that of the cylinder, so rapid flame growth can occur. When the burned gas completely fills the cylinder volume, then the change of burned gas volume is controlled by piston movement, which in the neighbourhood of TDC is small. Radiation on the other hand increases rapidly during this time because the rate of heat release is near its peak value, hence $\mathrm{CO}_{2}$ and $\mathrm{H}_{2} \mathrm{O}$ levels and temperature are near their maximum values. Upon reaching a maximum value, the radiation decreases less rapidly

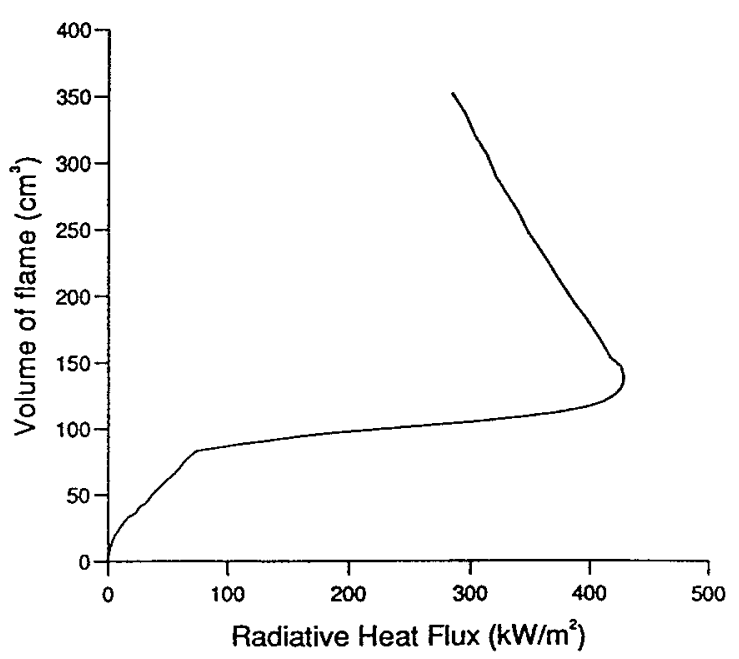

Figure 7 Volume of Flame vs. Radiative Heat Flux, Spark Timing $16^{\circ}$ BTDC (Base Line Condition)
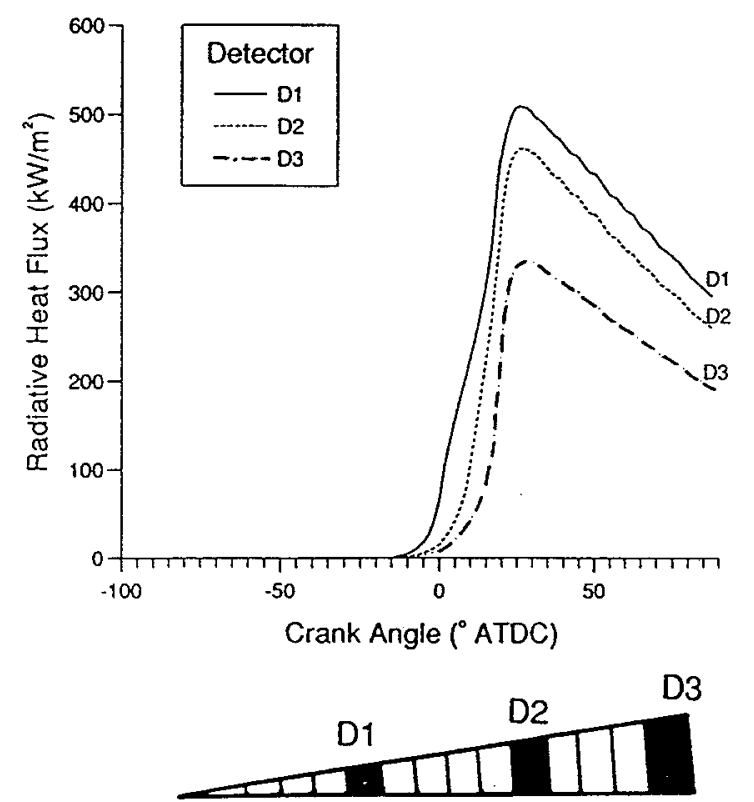

Points of

incident flux

Figure 8 Radiative Heat Flux vs. Crank Angle for Detectors in the Cylinder Head. Spark Timing $16^{\circ}$ BTDC 
as burned gas volume increases following piston motion during the expansion phase. The end of combustion can be taken as the region where the slope of the curve changes from a positive to a negative value. This occurs approximately at peak radiation intensity which coincides with the end of heat release, which is expected, as further formation of $\mathrm{H}_{2} \mathrm{O}$ and $\mathrm{CO}_{2}$ from the combustion process will cease, and concentration of these constituents in the flame volume will be at a maximum. Nutton and Pinnock [1] also identified peak luminosity with the end of burn from their experiments over a wide range of operating conditions.

The effect of change in detector position was investigated for the baseline condition, and the results shown in Figure 8 . Because the radiative heat flux at the cylinder head surface is being calculated, there will not be a significant difference in the phasing of peak radiative flux, as this will occur when combustion is complete and the flame will have traversed the combustion space. What is of interest, is the slower rise of radiative flux initially at the positions furthest from the cylinder axis, where the early view of the flame volume is poor. The decrease in magnitude of the radiative flux with increase in radius, reflects the variation in combustion gas temperature across the chamber.

The magnitude of peak radiative heat flux predicted here (Figure 5) under non-knocking conditions is approximately $450 \mathrm{~kW} / \mathrm{m}^{2}$ with a peak cylinder pressure of approximately 55 bar, stoichiometric air/fuel ratio and an operational speed of $1500 \mathrm{rpm}$. This compares well with the measured value of Baker and Laserson [7] of $260 \mathrm{~kW} / \mathrm{m}^{2}$ at a peak cylinder pressure of 15.5 bar (engine compression ratio was a low 4.6:1), air/fuel ratio of $12: 1$ and an operational speed of $1660 \mathrm{rpm}$. Using a mean beam length of $3.4 \times$ (swept volume/bore area) $\approx 30 \mathrm{~cm}$, and a constant temperature of approximately $2300 \mathrm{~K}$, the data of Hottel [17] is used to estimate the emissivities of $\mathrm{CO}_{2}$ and $\mathrm{H}_{2} \mathrm{O}$ for the differing peak cylinder pressures. The ratio of radiative heat fluxes can be approximated as the ratio of mean non-luminous grey gas emissivities, and is approximately equal to $0.39 / 0.23=1.69$.

\section{CLOSURE}

The magnitude of the radiative heat flux predicted over the engine cycle, and its variation with a range of engine operating variables has been shown to be consistent with measured data in which optical intensity was used as a diagnostic tool $[1,2]$ and also with direct measurement of infrared radiation [7].

The results obtained here suggest the possibility of using infrared radiation from the combustion products as a diagnostic tool and for the control of individual cylinder air/fuel ratio. While the grey gas model for radiation employed here did not allow individual contributions of either $\mathrm{CO}_{2}$ or $\mathrm{H}_{2} \mathrm{O}$ to be assessed over narrow bands of wavelength, this does not in anyway invalidate the conclusions arrived at above, as consideration of either of the two gases above over discrete wavelengths of interest, would simply result in a reduction in magnitude of the output radiative heat flux, which is well within the sensitivity of available fast response infrared detectors and associated signal amplifying equipment $[18,19]$. Of the two non-luminous infrared emitters in the combustion products, selection of $\mathrm{CO}_{2}$ for detection is to be preferred as it is inert and non-condensable. Hence, backflow into the cylinder of exhaust gases during valve overlap can be monitored, as well as exhaust gas recirculation.

Carbon dioxide emission at a wavelength centred on $4.3 \mu \mathrm{m}$ is extremely strong for hydrocarbon fuels, and detectors centred on this wavelength are readily available, as are suitable chalcogenide fibres [20].

Utilising a single detector and a branched fibre harness to individual cylinders of the engine, the cost of the system can be minimised, while providing an adequate signal gate of about $180^{\circ} \mathrm{CA}$ or $120^{\circ} \mathrm{CA}$ for 4 and 6 cylinder engines respectively. Here CFD has been deployed, with a consideration of a simple disc combustion chamber geometry in a spark ignition engine, to explore the potential for using infrared emission from the products of combustion in the engine cylinder as a diagnostic and control signal. The power of CFD can be further exploited to optimise the position of the infrared detector in a modern combustion chamber geometry for maximum signal output, and also in regard to the provision of an adequate cleansing gas flow over the small window surface necessary for infrared access to the cylinder.

\section{ACKNOWLEDGEMENT}

We wish to express our appreciation of support received for this work from the Science and Engineering Research Council of the United Kingdom.

\section{REFERENCES}

1. D. Nutton and R. A. Pinnock, Closed Loop Ignition and Fuelling Control Using Optical Combustion Sensors, S.A.E. Paper No. 900486 (1990).

2. D.J. Remboski, S.L. Plee and J.K. Martin, An Optical Sensor for Spark Ignition Engine Combustion Analysis and Control, SAE Paper No 890159 (1989).

3. K. Nakanishi, T. Hirano and T. Inoue, The Effects of Charge Dilution on Combustion and its Improvement -Flame Photograph Study, SAE Paper No 750054 (1975). 
4. J.B. Edwards, Combustion - Formation and Emission of Trace Species. Ann Arbor Science Publishers Inc. (1974).

5. H.C. Gerrish and F. Voss, Interrelation of Exhaust Gas Constituents. NACA Technical Report No 616 (1937).

6. C.F. Marvin, F.R. Caldwell and S. Steele, Infrared Radiation from Explosions in a Spark Ignition Engine, NACA Report No 486 (1934).

7. H.D. Baker and G.L. Laserson, An Investigation into the Importance of Chemiluminescent Radiation in Internal Combustion Engines, IMechE/ASME Proc. General Discussion on Heat Transfer, London (1951).

8. A.A. Amsden, P.J. O'Rourke and T.D. Butler, KIVA-II: A Computer Program for Chemically Reactive Flows with Sprays, Los Alamos National Laboratory Report LA-11560-MS (1989).

9. M.P. Halstead, L.L. Kirsch and C.P. Quinn, The Autoignition of Hydrocarbon Fuels at High Temperatures and Pressures - Fitting of a Mathematical Model, Combustion and Flame 30, pp 45-60 (1977).

10. H. Schäpertons and W.Lee, Multidimensional Modelling of Knocking Combustion in SI Engines, Paper No 850502, SAE Trans. (1985).

11. F.C.Lockwood and N.G.Shah, A new Radiation Solution Method for Incorporation in General Combustion Prediction Procedures, Eighteenth Symposium (Int.) on Combustion, The Combustion Institute, p1405, (1980).

12. J.S. Truelove, A Mixed Grey Gas Model for Flame Radiation. AERE Report No R8494, Harwell (1976).

13. W.L. Grosshandler, Radiative Heat Transfer in Non-Homogeneous Gases: A Simplified Approach. Int. Jour. Heat and Mass Trans., Vol. 23, p.1447 (1980).

14. C.A. Blunsdon, W.M. Malalasekera and J.C. Dent, Application of the Discrete Transfer Model of Thermal Radiation in a CFD Simulation of Diesel Combustion and Heat Transfer. Paper No 922305, SAE International Fuels and Lubricants Meeting, 19-22 October, San Francisco (1992).

15. S. Robinson, C.A. Blunsdon, J.C. Dent and C.P. Garner, Charge Coupled Device Camera/Computer Analysis of Flame Propagation in a Spark Ignition Engine, and some Comparisons with a Computational Fluid Dynamic Model. International Conference Computers in Engine Technology, Proc. IMechE 11 (1991).

16. S. Das and J.C. Dent, A CFD Study of a 4 Valved, Fuel Injected Two Stroke Spark Ignition Engine. SAE Paper No 930070 (1993).

17. W.H. McAdams, Heat Transmission, 3rd Ed. McGraw Hill (1954).

18. Infrared Detectors, 1991 Catalogue, Hamamatsu Photonics Ltd.
19. Characteristics and Use of Infrared Detectors. Technical Information SD-12 (1989). Hamamatsu Photonics Ltd.

20. Characteristics of Optical Fibres, Oxford Electronics Ltd. 